\title{
Upskilling of Pharmacy Faculty in an Accredited Institution through Modular Training in Strategic Education Practices with Formative and Summative Assessments
}

\author{
Bahubali Gundappa Nagavi', M. Chandra Sekar ${ }^{2, *}$ \\ ${ }^{1}$ Founder CEO \& Senior Consultant HESDAR Center, Mysuru, Karnataka, INDIA. \\ ${ }^{2}$ Professor, University of Findlay, Ohio, USA.
}

\begin{abstract}
Aim: To study the impact of Modular Faculty training on the attitude of faculty, motivation towards self-directed learning and team learning. Train the faculty on new teaching and learning tools and assessment. Assess the faculty continuously and after the completion of the training and distribute certificates as per the requirements informed in advance. Materials and Methods: Thirty two (32) faculty of an accredited college were enrolled in a 4 credit course consisting of 15 Modules with 60 contact hr workshop based program spread over about 06 months or 01 semester. Each workshop was of 4 to $5 \mathrm{hr}$ face to face interaction, including pre and post-tests, activities, presentations, discussions, reflections, flash card PPT and feedback. Important modules included were how to write good Learning Outcomes, Problem Based Learning (PBL), Blooms taxonomy, Soft skills, Leadership, Quality assurance and Academic advising to name a few. Formative assessment of $60 \%$ included Quiz, Assignment and mid module exam and summative assessment consisted of end module exam for $40 \%$ with MCQ's and RRE's (Restricted Response Essay). A minimum of $70 \%$ was assigned a C grade, $80 \%$ for B grade and $90 \%$ and above for A grade. Results: Twenty-seven faculty (27), 84\% completed the training and were awarded the certificate at a public function. Participants rated the program as effective, useful and need based. Average age of faculty in Indian pharmacy colleges is 32 to 34 and without any formal training in teaching and learning. Conclusion: Average pretest score in all the training modules was 4.2 and in post-tests the score rose to 9.6, indicating very clearly that training and upskilling was effective and raised the knowledge, skill and attitude of the participants. Institution paid a nominal fee for the training program, assessment and certification. As of now, in India there is no formal, modular and certificate based training imparted to faculty in about 2000 pharmacy colleges. If they are trained and upskilled, they will be able to impart more effective education and thereby transform the teaching and learning process in the pharmacy colleges. Key words: Up-skilling, Strategic Education Practices, Modular training and Assessment, Grading, MCQ and RRE.
\end{abstract}

\section{INTRODUCTION}

There is no formal training for the faculty in higher education, who teach and train students for over 30 years of their working career. If formally trained in key elements of teaching and learning with interpersonal skills, it will go a long way in motivating and transforming the faculty. In Indian scenario - regulatory bodies, professional organizations and others conduct Continuing Education Programs (CEP) or Continuing Professional Development (CPD) programs in research and related topics and education related areas.

Enhancing academic quality and practice have been discussed in detail by Heather Fry and others ${ }^{1}$ Many factors contribute to
Submission Date: 20-10-2019; Revision Date: 06-02-2020; Accepted Date: 14-04-2020

DOI: 10.5530/ijper.54.2s.63 Correspondence: Prof. Bahubali Gundappa Nagavi

Founder CEO \& Senior Consultant HESDAR Center, Mysuru, Karnataka, India. Phone: +91-0821-2470570 E-mail: hesdarcenter@gmail. com

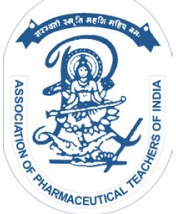

www.ijper.org 
the vitality of an individual faculty member, a department and an entire academic organization. ${ }^{2}$ Several factors contributing to role strain experienced by clinical nursing faculty while they oversaw the clinical experiences of nursing students. ${ }^{3}$ Nagy and Burch have explained academic work practices to enable knowledge building capacities in corporate universities have been discussed. ${ }^{4}$ The emergence of entrepreneurial cultures in European corporate universities have been discussed by Davies JL. ${ }^{5}$ In India, the duration of the programs is normally few days, that includes varied topics without focus and expected outcomes are neither listed nor measured. As a result, faculty undergoing such training lack confidence to deal with day to day issues in the institution and training is not tailored to specific age groups, qualification and experiences of the participants to provide the kind of training that is useful to the faculty. Instead, the training is general in nature for all age groups, qualification and experiences.

Hence attempt was made to address few of the important issues and needs of faculty in the presented training modules to update them with modern education techniques and tools to bring them in par with international standards. Informal and formal discussions were held with faculty and administrators to design need based and focused training modules. Existing training programs do not evaluate participant's prior knowledge and program outcomes are neither listed nor measured.

\section{Problems teachers face generally are listed below}

1. The curriculum we are given is very difficult to interpret. We don't know how much detail to teach.

2. The examinations encourage the students to learn facts rather than how to apply the facts.

3. The students are good at book learning, but they are weak when they face practical situations.

4. The courses are at too high level.

5. The teaching doesn't really train the students on how to do the job.

Modular workshops conducted made an attempt to discuss and create awareness about the above.

\section{MATERIALS AND METHODS}

The institution collaborating for the faculty training to be conducted by Higher education Skill Development and Research (HESDAR) center was reviewed in 2 site visits to list the strengths and challenges of individual institution, identify gaps especially with respect to faculty and their teaching and learning process. HESDARC's Vision, Mission, Goals and Objectives were shared with the faculty during orientation ses- sion. A road map of training was prepared in consultation with senior faculty and decision makers. In order to get long lasting impact - a certificate program with outcomes, topics, duration, contact hours, assessments and grading was discussed and agreed upon. The broad areas of engagement were listed leading to certification after successful completion of the training. The topics were also selected based on the feedback of the participants needs. Modules were designed and delivered in an interactive manner for best participation and active engagement by the faculty.

For each module the reading material of 6 to 8 pages was emailed to the participants for prior reading and reflection. Pretest for 20 marks was conducted for 20 min which had 10 MCQ's of 01 mark each and 03 RRE questions for 10 marks. The Pretest papers were evaluated by the participants. No one evaluated their own test paper.

\section{Average score of the faculty in pre-test was 4.2 on 10 indicating participants had very little knowledge about the topic.}

Workshop was then conducted with PPT presentation, activities, reflective sessions, guided activities, group discussion, presentations and Q and A session. Each workshop was for about 4 to $5 \mathrm{hr}$ with a break of $10 \mathrm{~min}$. After the workshop post test was conducted with the same question paper used for pre-test. Average score rose from 4.2 to 9.6 in post-test indicating that participant's knowledge, skill and attitude about the topic improved significantly. Feedback was received from the participants regarding the topic, outcomes and the session as a whole. A formal report was sent to the participants about the modular training with indicators of progress in learning - 15 different modules were covered over about 06 months. Continuous assessments - Quiz, Assignment and Mid- module exam was conducted during the program and end modules exam of about $2 \mathrm{hr}$ with MCQ's and RRE was held and used for grading purpose.

\section{RESULTS AND DISCUSSION}

Training modules which were delivered to the participants are listed in Table 1. The modules were developed and delivered based on the needs of the participants and their feedback and suggestions at the end of each module. Some of the suggestions given by the participating faculty are listed in Table 2. Table 3 lists four things which are very important in teaching and were discussed in the workshops.

It was discussed and made very clear that unless the learning and training is tested and measured, there 


\section{Table 1: Modules included in the workshop.}

1. Faculty development - Values, Purpose and Process

2. Soft / Interpersonal Skills in Higher Education

3. Good Scientific Speaking Practices

4. How to Write Good Program Learning Outcomes

5. Assessment, related frauds and how to manage

6. How to write effective Course Learning Outcomes

7. Leadership, Attitude, Motivation and Performance (LAMP)

8. Problem Based Learning 1- Introduction, Objectives, Learning Outcomes

9. Problem Based Learning 2 - Process, Assessment, Feedback

10. Classroom Management, Student Engagement and Dealing with difficult students

11. Quality Assurance of Pharmacy education and International Standards

12. Academic Advising - What matters to students?

13. Academic Advising - Process, Issues, Assessment and Feedback

14. Combatting Academic Corruption

15. Study Plan and Course Description - How, 16.

17. Academic Research - What and How?

\section{Table 2: Some of the key suggestions and feedback} by the participants.

1. How to teach students and help them to overcome learning defects

2. Handling students in effective manner

3. Learning material development and how to accommodate within day to day limitations

4. Interpersonal relations and Time Management

5. Multitasking, Prioritizing and Meeting deadlines

6. Written communication Skills and Team work and Communication

\section{Table 3: Four things which are very important in} teaching.

1. Deciding exactly what the students should learn.

2. Choosing and using suitable teaching methods.

3. Testing whether students can do the work for which they are being trained.

4. Preparing teaching materials and manuals.

will be no significant change. The popular saying is "What gets measured is improved". Most of the training programs conducted in the country do not measure systematically and continuously. Table 4 gives the formative and summative assessment techniques used during the training period. Participants whole heartedly took part in the assessments.

Out of 32 registered participants, 27 completed all the modules and scored $\mathrm{C}$ grade or above. Remaining

\section{Table 4: Assessment and Grading.}

1. Continuous Assessment: 60 \% ( 1 Quiz, 1 Assignment and 1 Mid-modules Assessment)

2. End/Modules Assessment: $40 \%$

3. Assessment includes: MCQ's and Short Answers (70:30). All assessments were hard copy based. Attempt is being made. To develop computer or smart phone and App based testing.

4. Grading

Range Grade Merit G.P

$95 \%$ and above A+ Outstanding 10

90.00 to $94.99 \%$ A Excellent 9

85.00 to $89.99 \%$ B + Very Good 8

80.00 to $84.99 \%$ B Good 7

75.00 to $79.99 \%$ C+ Satisfactory 6

70.00 to $74.99 \%$ C Pass 5

Below $70.00 \%$ \% F Fail 4

participants (5) could not complete due to low score/ performance in formative or summative assessments. Only 01 participant received A grade, few got B+ and $\mathrm{B}$ grades. Majority were in $\mathrm{C}+$ and $\mathrm{C}$ grade. Some of the reasons for low performance were lack of preparedness for quiz/tests, assignment submission, low performance in mid module or end module exam. Certificates were awarded in a public function to the successful participants and others who did not succeed were encouraged to retake the exam/s. Each certificate included HESDARC logo, College logo, participant's photo, grade, grade point, percentage and merit scored. The list of modules was indicated with contact hours, credit and signatures of competent authority from HESDARC and the college.

\section{ACKNOWLEDGEMENT}

Authors thank Acharya BM Reddy College of Pharmacy, Prof. Divakar Goli Campus Director, Prof. Giles Principal College of Pharmacy and faculty members for their active engagement and participation

Authors also thank HESDARC's IT Team especially Mr. Kalpesh V Mehta and Mr. Aamer Zahir for their support - software development, deployment in the implementation of the training and reports.

\section{CONFLICT OF INTEREST}

The authors declare no conflict of onterest.

\section{ABBREVIATIONS}

PBL: Problem Based Learning; MCQ: Multiple Choice Questions; RRE: Restricted Response Essay. 


\section{REFERENCES}

1. Heather FRY, Steve KSM. Simultaneously published in the UK by Routledge A Handbook for Teaching and Learning in Higher Education Enhancing academic and Practice - Enhancing Academic Practice, Third edition. 2009.

2. Shane PD, Gretchen LP, Brian LC, Daniel A, JrJohnnie LE, JrAndrew A, et al. Pharmacy Faculty Workplace Issues: Findings From the 2009-2010 COD-COF Joint Task Force on Faculty Workforce. Am J Pharm Educ. $2011 ; 75(4): 63$
3. Piscopo B. Organizational climate, communication and role strain in clinical nursing faculty. J Prof Nurs. 1994;10(2):113-9.

4. Nagy J, Burch T. Communities of Practice in Academe (CoP-iA): Understanding academic work practices to enable knowledge building capacities in corporate universities. Oxford Rev Educ. 2009;35(2):227-47.

5. Davies JL. The emergence of entrepreneurial cultures in European universities. Journal of the Programme on Institutional Management in Higher Education. 2001;13(2):25-44.

\section{PICTORIAL ABSTRACT}

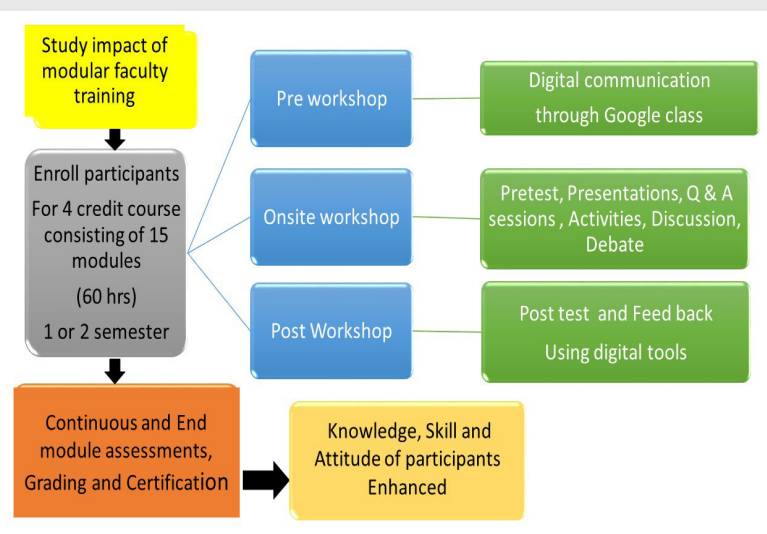

\section{SUMMARY}

A modular training program was designed and delivered for the $1^{\text {st }}$ time in India with a minimum of 60 face to face contact hours, 4 credits with formative and summative assessments. A minimum of 15 modules were presented in workshop format with guided activities, reflective time, discussions and presentations. 27 of the 32 enrolled completed the training program and were awarded participation and Merit certificates.

Participants wanted more such programs, especially to young faculty so that they are well informed, motivated and transformed - to meet the challenges of modern higher education and to be in par with international standards.

\section{About Authors}

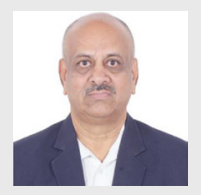

Dr. Bahubali G Nagavi. M Pharm PhD, is currently working as CEO of Higher Education Skill Development And Research Center (HESDARC), Mysuru, Karnataka. He was Dean at RAKMHS University, UAE \& Principal of JSS College of Pharmacy Mysuru. Dr Nagavi, for over 40 years was Teacher, Researcher, Trainer, Guide \& Administrator. He was Editor of IJPER, National VP of IPA. Dr. Nagavi conducts Onsite \& Online training programs for faculty in education, technology, PBL, education research \& digital tools etc.

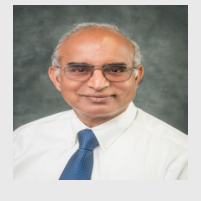

Dr. M. Chandra Sekar, R.Ph., Ph.D., is currently a Professor and the International Ambassador for Pharmacy Education for the University of Findlay, OH, USA. He was selected as Fellow of American Pharmacists Association in 2013 and was awarded the Indian Pharmacists Association's M. L. Khorana Memorial award in 2018 and made a Fellow of Indian Pharmacist Association in 2019.

Cite this article: Nagavi BG, Sekar MC. Upskilling of Pharmacy Faculty in an Accredited Institution through Modular Training in Strategic Education Practices with Formative and Summative Assessments. Indian J of Pharmaceutical Education and Research. 2020;54(2s):s75-s78. 